\title{
SOSIALISASI PENTINGNYA PENGGUNAAN KB DALAM KESEHATAN REPRODUKSI DI KELURAHAN MAHARANI KECAMATAN RUMBAI KOTA PEKANBARU
}

\author{
Intan Widya Sari ${ }^{1)}$ Riza Febrianti ${ }^{2)}$ \\ STIKes Hang Tuah Pekanbaru \\ Email : intanwidya@htp.ac.id
}

\begin{abstract}
The right to reproductive health is a human right that should be obtained by the community, especially family planning (KB) acceptors through quality family planning services which are a government program. From the data obtained, the problems found in RT 002 Maharani Village, Rumbai District, Pekanbaru City. The majority of the population in RT 002 does not use family planning. Of the 48 PUS, only 10 PUS used contraception, 38 PUS did not use contraception. The purpose of this activity is to help mothers who do not have family planning to use contraceptives. The method used in this community service is a question and answer lecture using leaflets. After the socialization, it is hoped that it can increase the knowledge and enthusiasm of the residents about family planning.
\end{abstract}

Keywords: Family Planning, PUS, Reproductive Health

\begin{abstract}
ABSTRAK
Hak kesehatan reproduksi adalah hak asasi manusia yang seharusnya diperoleh masyarakat khususnya akseptor Keluarga Berencana (KB) melalui pelayanan KB berkualitas yang menjadi program pemerintah. Dari data yang didapatkan bahwa permasalahan yang terdapat di RT 002 Kelurahan Maharani Kecamatan Rumbai Kota Pekanbaru. Mayoritas penduduk di RT 002 tidak menggunakan KB. Dari 48 PUS hanya 10 PUS yang menggunakan alat kontrasepsi, 38 PUS yang tidak menggunakan alat kontrasepsi. Tujuan pelaksanaan kegiatan ini yaitu membantu para ibu yang tidak ber-KB untuk dapat menggunakan alat kontrasepsi. Metode yang digunakan dalam pengabdian masyarakat ini adalah ceramah tanya jawab dengan menggunakan leaflet. Setelah sosialisasi diharapkan dapat meningkatkan pengetahuan dan antusias warga terhadap KB.
\end{abstract}

Kata Kunci : Keluarga Berencana, PUS, Kesehatan Reproduksi 


\section{PENDAHULUAN}

Hak kesehatan reproduksi adalah hak asasi manusia yang seharusnya diperoleh masyarakat khususnya akseptor Keluarga Berencana (KB) melalui pelayanan $\mathrm{KB}$ berkualitas yang menjadi program pemerintah. Pelayanan berkualitas termasuk kualitas medik, artinya menawarkan metode kontrasepsi yang cocok dengan pelayanan yang tersedia, ditunjang dengan konseling yang tepat, dan tenaga penyelenggaranya (provider) yang berkompeten secara teknis. Pelayanan juga harus mengakomodasi harapan perempuan yang membutuhkan hubungan interpersonal agar dapat diketahui pandangan dan pendapat perempuan tersebut (POGI, 2003).

$\begin{array}{rrr}\text { Program } & \text { KB } & \text { bertujuan } \\ \text { mengendalikan } & \text { fertilitas } & \text { yang }\end{array}$
membutuhan metode kontrasepsi yang berkualitas agar dapat meningkatkan kesehatan reproduksi dan kesehatan seksual. Pelaksanaannya dipengaruhi sumberdaya pelaksanaan program $\mathrm{KB}$, cara pandang masyarakat sendiri terhadap kesehatan reproduksi dan pelayanan $\mathrm{KB}$, serta pemakaian alat kontrasepsi. Badan Kependudukan Keluarga Berencana Nasional (BKKBN) merupakan badan yang diberi tanggung jawab dalam pengaturan laju pertambahan penduduk. BKKBN memiliki visi "Seluruh Keluarga Ikut KB" dan misi baru BKKBN yaitu "Mewujudkan Keluarga Kecil Bahagia dan Sejahtera". Kementerian Kesehatan memiliki kewajiban menindaklanjuti tugas BKKBN dengan memberikan pelayanan KB kepada masyarakat yang membutuhkan (BKKBN, 2010).

Kesehatan reproduksi adalah suatu keadaan sejahtera fisik,mental,dan sosial secara utuh tidak semata-mata bebas dari penyakit atau kecacatan dalam suatu yang berkaitan dengan system reproduksi, fungsi dan prosesnya (WHO).

Kesehatan Reproduksi adalah suatu keadaan sehat mental, fisik dan kesejahteraan sosial secara utuh pada semua hal yang berhubungan dengan sistem dan fungsi serta proses reproduksi dan bukan hanya kondisi yang bebas dari penyakit dan kecacatan serta dibentuk berdasarkan perkawinan yang sah, mampu memenuhi kebutuhan spiritual dan material yang layak, bertakwa kepada Tuhan Yang Maha Esa, spiritual yang memiliki hubungan yang serasi, selaras dan seimbang antara anggota keluarga dan antara keluarga dengan masyarakat dan lingkungan (BKKBN,1996).

Keluarga Berencana merupakan suatu tindakan yang membantu seseorang 
maupun pasangan suami isteri untuk mengindari kelahiran yang tidak harapkan, mendapatkan kelahiran yang diinginkan pasutri, mengatur interval atau jarak diantara kelahiran, mengontrol waktu pada saat kelahiran yang berhubungan dengan umur suami dan istri, menetukan jumlah anak. Sumber ; WHO (World Health Organisation.

Dari data yang didapatkan bahwa permasalahan yang terdapat di RT 002 Kelurahan Maharani Kecamatan Rumbai Kota Pekanbaru. Mayoritas penduduk di RT 002 tidak menggunakan KB. Dari 48 PUS hanya 10 PUS yang menggunakan KB , 38 PUS yang tidak mengunakan KB. Dimana hal ini dapat menimbulkan peningkatan angka kelahiran, sehingga dapat menimbulkan efek negative dari berbagai sisi, seperti mengancam kesehatan reproduksi ibu, meningkatkan resiko kematian ibu dan bayi, dan mengganggu perekonomian masyarakat.

Dukungan yang menunjang wanita untuk membuat keputusan yang berkaitan dengan proses reproduksi, berupa pengadaan informasi dan pelayanan yang dapat memenuhi kebutuhan untuk mencapai kesehatan reproduksi secara optimal.

\section{METODE PENERAPAN}

Dalam kegiatan pengabdian ini metode yang digunakan adalah dalam bentuk penyuluhan berupa sosialisasi dan metode demonstrasi dengan menggunakan leaflet, lembar balik dan phantom. Materi yang diberikan dalam sosialisasi adalah tentang kesehatan reproduksi dan pentingnya untuk ber-KB. Pelaksaan sosialisasi di lakukan sesuai dengan materi kesehatan reproduksi dan KB.

\section{HASIL DAN PEMBAHASAN}

\section{A. Hasil Pelaksanaan}

Kegiatan

sosialisasi pentingnya penggunaan $\mathrm{KB}$ ini telah di laksanakan pada tanggal 26 November 2019 pada 25 orang PUS yang di berikan penjelasan tentang KB.

Berdasarkan pengamatan selama kegiatan berlangsung, kegiatan pegabdian pada masyarakat ini memberikan hasil sebagai berikut :

1. Meningkatnya pengetahuan dan pemahaman PUS mengenai pentingnya ber-KB bagi kesehatan reproduksi, dan PUS memahami bahwa dengan berKB memiliki banyak manfaat seperti dapat mengatur jarak kehamilan, menjaga kesehatan reproduksi ibu, serta menurunkan angka kematian ibu dan bayi . Hal ini dilihat dari kemampuan dan semangat 
PUS dalam menjawab pemateri.

pertanyaan yang diajukan oleh

2. Meningkatnya Rasa ingin ber-KB PUS setelah dilaksanakannya sosialisasi ini.
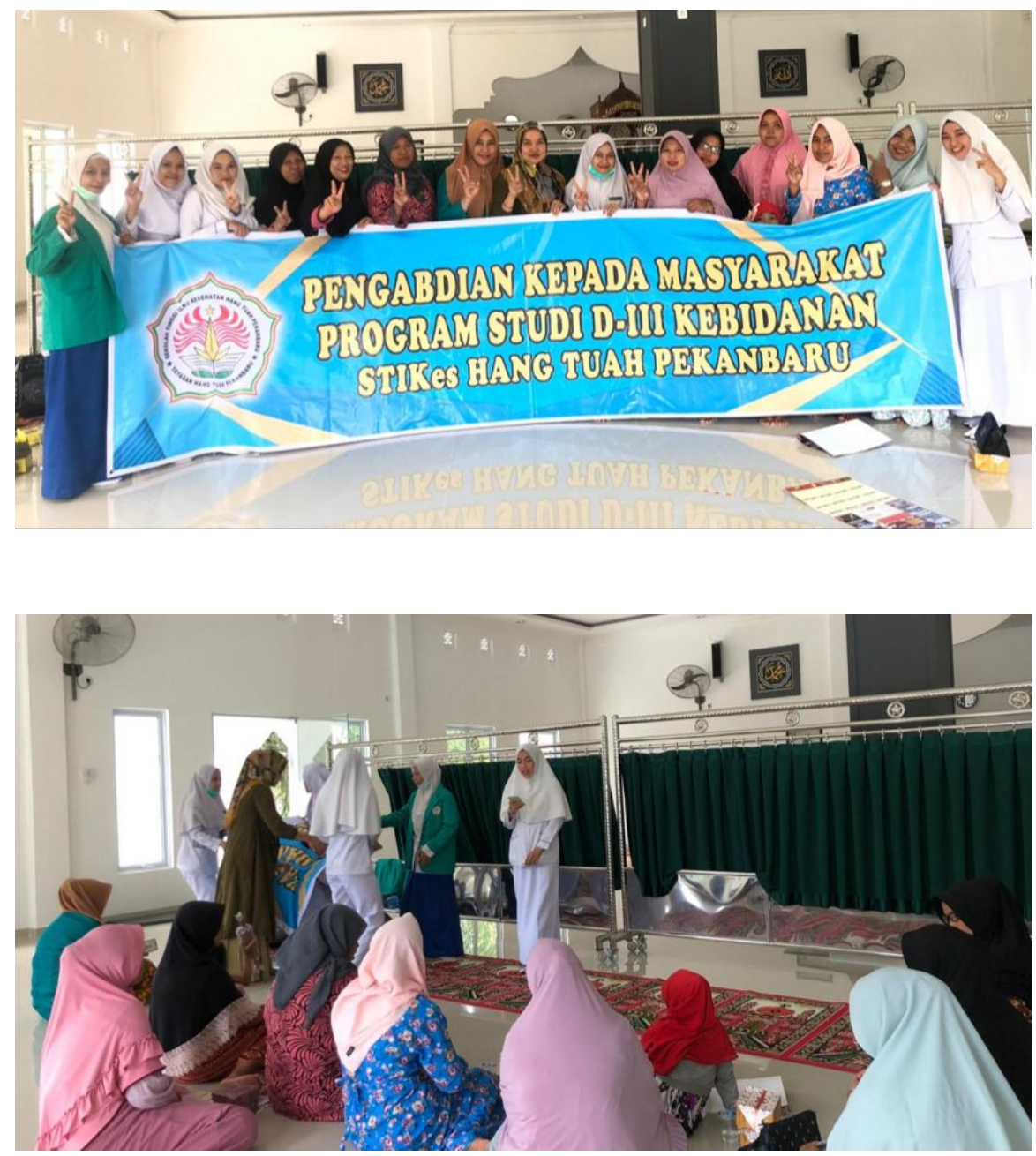

\section{B. Pembahasan}

Keluarga berencana adalah tindakan yang membantu individu untuk mendapatkan objek-objek tertentu, menghindari kehamilan yang tidak diinginkan mendapatkan kehamilan yang diinginkan, mengatur interval kehamilan, menentukan jumlah anak dalam keluarga, mengontrol saat kelahiran dalam hubungan dengan umur suami istri. Kontrasepsi adalah upaya untuk mencegah terjadinya kehamilan, alat yang digunakan untuk menunda kehamilan dan menjarangkan jarak kelahiran.

Pada pelaksanaan pengabdian masyarakat ini didapatkan mayoritas penduduk tidak menggunakan $\mathrm{KB}$, minimnya pengetahuan dan pemahaman warga tentang $\mathrm{KB}$ dan diharapkan 
sosialisasi ini meningkatkan

KB dalam Kesehatan Reproduksi.

pengetahuan ibu tentang pentignya
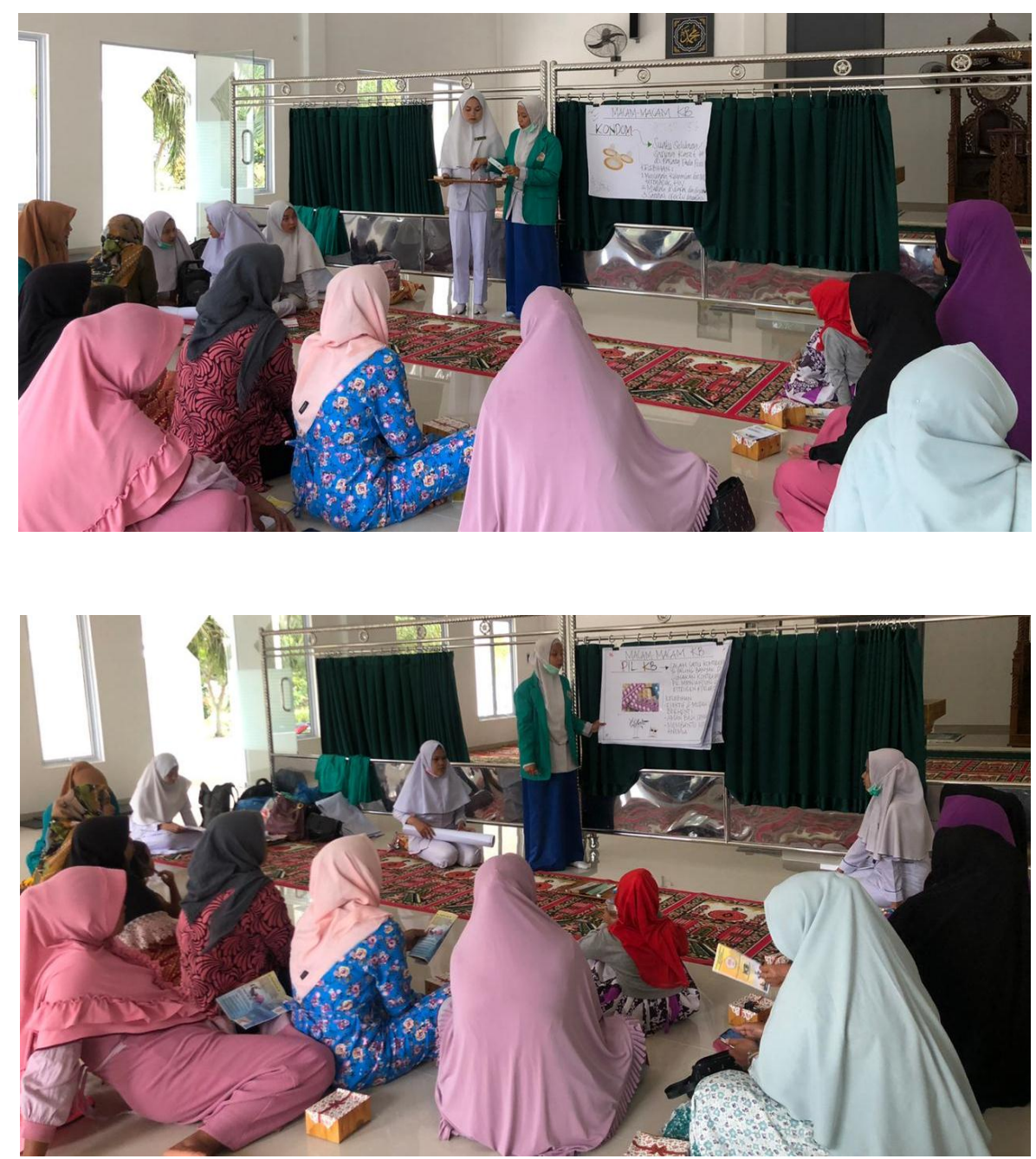

\section{KESIMPULAN}

Dapat disimpulkan bahwa:

1. Mayoritas penduduk tidak menggunakan $\mathrm{Kb}$

2. Minimnya pengetahuan dan pemahaman warga tentang KB

3. Sosialisasi ini meningkatkan pengetahuan ibu tentang pentignya KB dalam Kesehatan Reproduksi

\section{DAFTAR PUSTAKA}

https://www.academia.edu/105248 63/SATUAN_ACARA_P ENYULUHAN_SAP_TE NTANG_KB_KELUARG A_BERENCANA?auto $=\mathrm{d}$ ownload

BKKBN,1999.Kependudukan KB dan KIA. Bandung, Balai Litbang 
Hartanto, Hanafi. 2004. Keluarga

Berencana dan

Kontrasepsi.

Prawirohardjo, Sarwono.2006.

Buku Panduan Praktis

Pelayanan
Kontrasepsi.Jakarta:Yayas

an Bina Pustaka

http://rizanurzaman.blogspot.com/2 012/11/sejarah-keluarga berencana.html

http://nurelfata.blogspot.com 